\title{
Mouse genome roars ahead with new map
}

Declan Butler

The public-domain effort to sequence the mouse genome is set to accelerate, following the completion of a physical map of the genome.

Sequence data flowing from the international Mouse Sequencing Consortium can now be anchored to the map, speeding up assembly of the complete genome. The project is the first to use human-genome data as a framework to build a map of another genome, and provides a proof-ofprinciple that will speed up completion of the genomes of other species.

The map, which offers a complete tiling path for each chromosome, is available at the Ensembl database (see below). In it, the 290,000 bacterial clones in the sequence have been assembled into just 554 contiguous blocks, or contigs, spanning 3,080 megabases - $98 \%$ of the entire mouse genome. This relatively small number of contigs will make it easy to assemble the full genome, researchers say.

The low number of contigs and the speed with which the map has been completed can be attributed to the usefulness of the human genome sequence as a guide, say members of the multicentre team that created the map. Mouse genes align well with human ones, and long blocks of the sequence are common to both genomes. The team used information from these common blocks to help them place and orientate the mouse-clone contigs; this enabled them to reduce the number of contigs from more than 7,000 .

In turn, the mouse map is also helping to plug remaining gaps in the human genome sequence. By aligning the mouse map next to the human sequence, mouse contigs have already been identified as spanning gaps in the human genome.

The availability of the mouse map means that assembly of the entire mouse genome can proceed apace. The Mouse Sequencing Consortium is generating sequence by applying the high-throughput 'shotgun' sequencing method pioneered by Celera Genomics of Rockville, Maryland, using

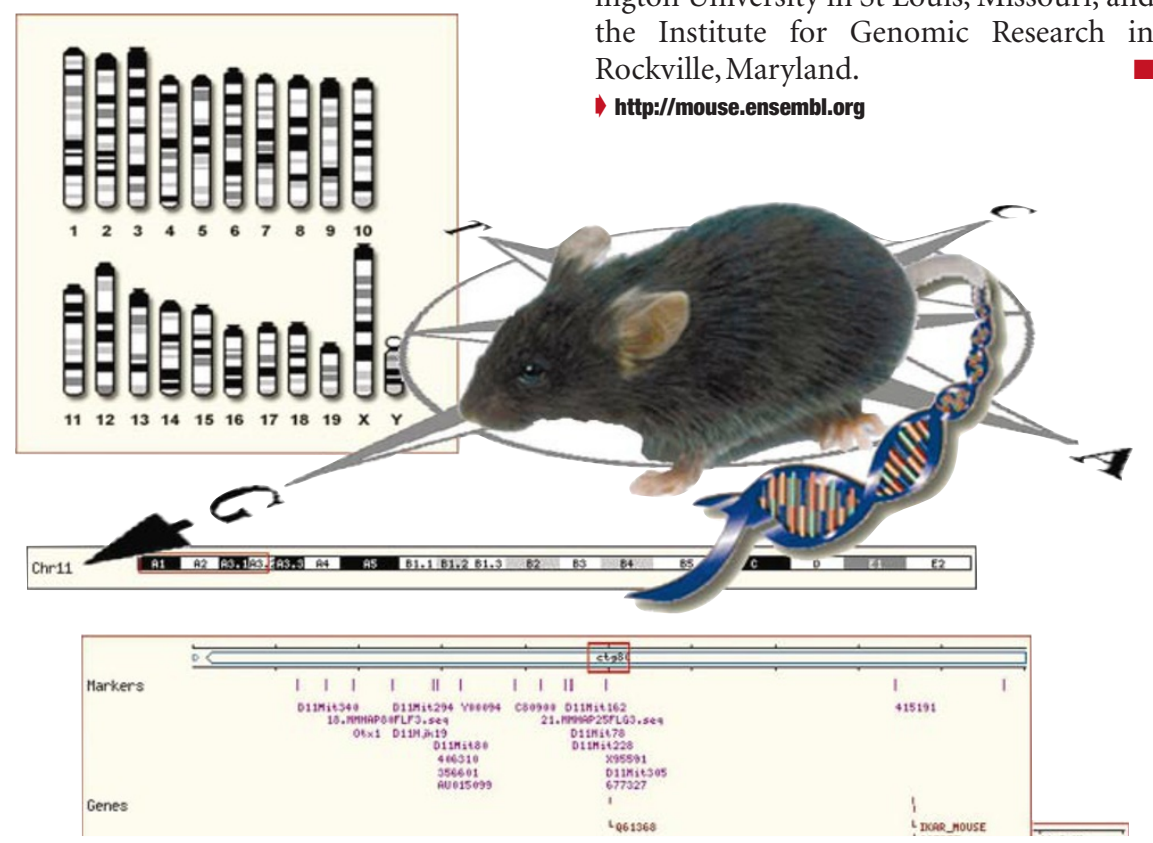

Points of reference: work on the mouse genome is helping to fill gaps in the human genome sequence. 700 bases long (see Nature 411, 121;2001).

"We can now nail the emerging mouse assemblies to the map," says Tim Hubbard of the Sanger Centre near Cambridge in England. Hubbard expects to have produced a rough first bash at the entire genome within the next few weeks, with continual refinement over the coming months.

The map was generated by groups at the Sanger Centre; the Genome Sequence Centre in British Columbia, Canada; Washington University in St Louis, Missouri; and the Institute for Genomic Research in Rockville, Maryland.

http://mouse.ensembl.org some 6 million fragments between 500 and

\section{Psychiatrist launches lawsuit over 'academic freedom'}

David Spurgeon, Montreal

A psychiatrist who had a job offer withdrawn by a hospital affiliated to the University of Toronto, after making critical comments about psychotropic drugs such as

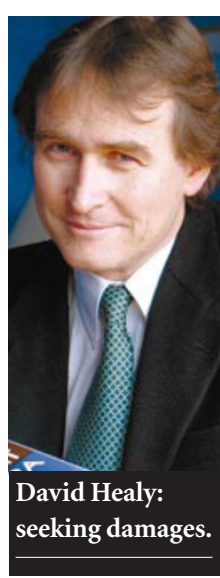
Prozac, has announced that he will sue the university and the hospital for damages of Can\$9.4 million (US\$6 million).

Lawyers acting for David Healy, of the University of Wales College of Medicine, have filed a statement of claim asking Canada's Superior Court of Justice in Toronto for formal recognition of an academic's right to speak out without fear of losing his or her position or of being reprimanded.

The lawyers say that this lawsuit is the first to be filed in Canada based on the principle of academic freedom.

Healy claims that the university and its affiliated hospital, the Centre for Addiction and Mental Health (CAMH) contravened this principle and broke their contract with him (see Nature 413, 240; 2001).

The lawsuit further alleges that Healy, director of the North Wales department of psychological medicine in Bangor, was defamed as a scientist and as a physician during attempts by the hospital and the university to justify the decision to withdraw his job offer.

In September 2000, Healy accepted the post of clinical director of the mood and anxiety disorders programme at the $\mathrm{CAMH}$, with an accompanying full professorship in the university's department of psychiatry.

According to the statement of claim, the contract was rescinded in an e-mail a week after Healy gave an invited lecture at a November colloquium at the centre.

The CAMH has issued a statement saying that it stands by its decision, which was based "solely on the needs of our patients and staff".

University officials have said that Healy would still be offered an academic appointment if he obtained an appropriate medical position in one of the university's affiliated teaching hospitals.

Healy told a press conference in Toronto on 24 September that he did not intend to profit from the lawsuit. Instead, he said, he would use the proceeds - after costs and "immediate damages" - to set up a trust fund "to promote academic freedom". 